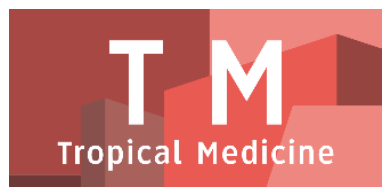

PAPER - OPEN ACCESS

\title{
Profil Asam Lemak Jenuh pada Produk Makanan Turunan Minyak Kelapa Sawit di Indonesia
}

\author{
Author : : Ahmad Gazali Sofwan Sinaga \\ DOI $\quad: 10.32734 /$ tm.v1i1.70 \\ Paper Page : $306-312$
}

Volume 1 Issue 1 - 2018 TALENTA Conference Series: Tropical Medicine (TM)

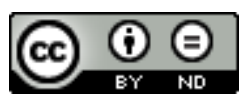

This work is licensed under a Creative Commons Attribution-NoDerivatives 4.0 International License.

Published under licence by TALENTA Publisher, Universitas Sumatera Utara
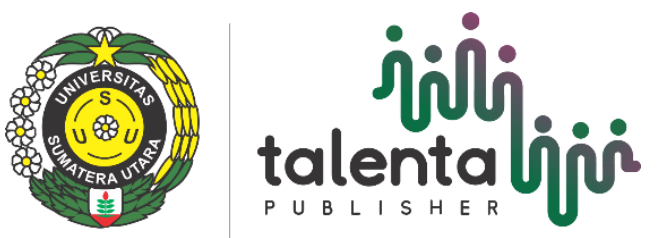


\title{
inili talentaljoi TALENTA Conference Series \\ Available online at https://talentaconfseries.usu.ac.id \\ Profil Asam Lemak Jenuh pada Produk Makanan Turunan Minyak Kelapa Sawit di Indonesia
}

\author{
Ahmad Gazali Sofwan Sinaga ${ }^{a}$ dan Donald Siahaan ${ }^{\mathrm{a}}$ \\ ${ }^{1}$ Pengolahan Hasil dan Mutu, Pusat Penelitian Kelapa Sawit 20158, Indonesia \\ gazalisofwan@gmail.com
}

\begin{abstract}
Abstrak
Asam lemak jenuh dapat dikaitkan dengan peningkatan kadar kolesterol darah yang berakibat pada penyakit jantung koroner. Minyak nabati seperti kelapa sawit mengandung asam lemak jenuh dan asam lemak tidak jenuh tunggal yang tinggi. Minyak tersebut banyak digunakan dalam proses pembuatan makanan seperti biskuit, makanan ringan, dan cokelat yang beredar di pasar.Penelitian ini bertujuan untuk menentukan kandungan asam lemak jenuh pada beberapa produk makanan yang mengandung turunan minyak kelapa sawit. Sebanyak 56 produk makanan terdiri dari biskuit, makanan ringan, produk cokelat, minyak goreng, margarin dan shortening diperoleh dari pasar di Indonesia. Lemak atau minyak yang terdapat pada produk diekstrak dengan heksan menggunakan sokhlet dan dianalisis menggunakan gas kromatografi. Hasil menunjukkan seluruh sampel mengandung turunan minyak kelapa sawit, berdasarkan profil komposisi asam lemak. Seluruh sampel biskuit, makanan ringan, mi instan dan produk cokelat memiliki kandungan asam lemak jenuh rendah $(0,468-9,715 \mathrm{~g} /$ takaran saji), karena kemungkinan tidak menggunakan campuran fraksi minyak sawit stearin. Satu dari 12 minyak goreng mengandung campuran minyak kelapa, namun menunjukkan kandungan asam lemak jenuh yang rendah $(2,137-6,488 \mathrm{~g} / \mathrm{takaran}$ saji). Enam dari 8 sampel margarin mengandung asam lemak jenuh tinggi (5,763 - 17,166 g/takaran saji), kemungkinan dalam proses pembuatan menggunakan campuran minyak kelapa dan minyak inti sawit. Seluruh sampel shortening memiliki kandungan asam lemak jenuh tinggi (13,651 - 14,963 g/takaran saji), karena menggunakan campuran minyak sawit dan minyak inti sawit. Secara umum, seluruh sampel mengandung asam lemak jenuh rendah dibawah $20 \mathrm{~g} /$ takaran saji berdasarkan Nutrient Reference Values(NRVs).
\end{abstract}

Kata Kunci: Asam lemak jenuh, minyak kelapa sawit, minyak inti sawit, Nutrient Reference Value;

\section{Pendahuluan}

Salah satu komponen utama makanan yang memberikan dampak positif dan negatif terhadap kesehatan adalah lemak yang mempunyai multifungsi, yaitu sebagai penyumbang energy terbanyak $(30 \%$ atau lebih darienergitotal yang diperlukan tubuh) serta merupakan sumber asam lemak esensial linoleat dan linolenat. Selain sebagai pelarut vitamin A, D, E dan K, lemak memberikan cita rasa dan aroma spesifik pada makanan yang tidak dapat digantikan oleh komponen makanan lainnya.Sedangkan dampak negatif dari konsumsi lemak yang berkaitan dengan aterogeni dapat terjadi bila konsumsi lemak lebih dari $30 \%$ dari kebutuhan energitotal (Mayes, 2003).

Asam lemak jenuh merupakan asam lemak yang tidak memiliki ikatan rangkap pada atom karbon yang menyebabkan asam lemak peka terhadap oksidasi dan pembentukan radikal bebas. Secara umum makanan yang berasal dari hewani (daging berlemak, keju, mentega, dan krim susu) selain mengandung asam lemak jenuh juga mengandung kolesterol. Asam lemak jenuh selain banyak ditemukan pada lemak hewani, juga dapat ditemukan 
pada minyak kelapa dan minyak kelapa sawit (Sartika, 2008). Konsumsi lemak total maksimal per hari yang dianjurkan adalah 30\% dari energi total, yang meliputi 10\% asam lemak jenuh, $10 \%$ asam lemak tidak jenuh tunggal, dan 10\% asam lemak tidak jenuh majemuk (Lichtenstein et al., 2006).

Minyak kelapa sawit mengandung jumlah komposisi asam lemak jenuh dan asam lemak tidak jenuh yang seimbang. Minyak kelapa sawit berbeda dengan beberapa minyak nabati lainnya yaitu mengandung sekitar $44 \%$ asam palmitat dan sekitar 6\% asam stearat dari total asam lemak (Nusantoro,2009). Minyak kelapa sawit memiliki potensi aplikasi yang luas dan biasanya difraksinasi menjadi bentuk olein dan stearin sebelum digunakan dalam beberapa produk pangan (Dauqan et al, 2011). Fraksi olein diperoleh dari proses pemurnian minyak kelapa sawit dengan kandungan asam oleat sekitar 42,7\% - 43,9\%, sedangkan fraksi stearin berbentuk lebih padat karena memiliki titik lebur yang tinggi dan secara umum mempunyai sifat konten lemak padat yang tinggi. Secara umum fraksi minyak kelapa sawit tersebut sering ditemukan pada susu, krim, butter, keju, pie, biskuit, kue dan roti.

Penggunaan produk turunan minyak kelapa sawit sebagai bahan baku pada produk makanan merupakan salah satu pilihan dalam perkembangan industri pangan di dunia. Namun di beberapa negara di Eropa telah menerapkan peraturan untuk membatasi asupan asam lemak jenuh terutama yang berasal dai minyak kelapa sawit. Berdasarkan European Food Safety Authority (EFSA Panel on Dietetic Products, Nutrition, and Allergies, 2010), penggunaan asam lemak jenuh seharusnya kurang dari $10 \%$ dari total asupan lemak. Berdasarkan Nutrient Reference Values, penggunaan asam lemak jenuh pada beberapa produk makanan harus kurang dari $20 \mathrm{~g}$ dalam takaran saji. Beberapa regulasi yang telah ditetapkan di Eropa tersebut dianggap mempersulit posisi minyak kelapa sawit dalam penggunaan sebagai bahan baku produk makanan dan sulit bersaing dengan beberapa produk minyak nabati lainnya.

Saat ini, Indonesia belum memiliki peraturan terkait jumlah maksimum asam lemak jenuh yang terdapat pada produk makanan. Berdasarkan hal tersebut, penelitian ini bertujuan untuk menentukan kandungan asam lemak jenuh pada produk makanan yang mengandung turunan minyak kelapa sawit yang beredar di Indonesia. Informasi tersebut tidak hanya penting bagi konsumen tetapi juga berguna untuk para ahli gizi dan industri pangan di Indonesia

\section{Metode Penelitian}

\subsection{Persiapan Sampel}

Sebanyak 56 sampel biskuit, mi, cokelat, makanan ringan, margarin, minyak goreng, dan shortening yang mengandung turunan minyak kelapa sawit diperoleh dari pasar lokal di Indonesia. Makanan tersebut disimpan pada suhu yang sesuai (suhu dingin). Seluruh makanan dianalisis sebanyak dua kali.

\subsection{Bahan dan Alat}

Standar analisis asam lemak yang digunakan diperoleh dari Sigma Chemicals. Seluruh reagensia dan pelarut yang digunakan diperoleh dari Merck Emsure seperti natrium hidroksida $(\mathrm{NaOH})$, bromotrifluoride (BF3), natrium klorida $(\mathrm{NaCl})$, n-heksana, dan metanol bersifat pro analisis. Alat yang digunakan dalam penelitian ini adalah alat-alat gelas laboratorium (Pyrex), kromatografi gas (Shimadzu), soxhlet extractor, dan kolom kromatografi DB-23 (30 m x 0,250 mm) (Agilent).

\subsection{Prosedur Ekstraksi Lemak}

Ekstraksi lemak dari sampel produk makanan dilakukan dengan menggunakan n-heksana sebagai pelarut melalui proses sokletasi. Sebanyak 10 gram sampel dimasukkan ke dalam labu ekstraksi dan ditambahkan n-heksana sejumlah $200 \mathrm{ml}$ yang kemudian diletakkan pada tabung ekstraktor. Lemak diekstraksi selama 8 jam pada suhu 
sekitar $60-70^{\circ} \mathrm{C}$ hingga diperoleh ekstrak kental. Kandungan lemak total dihitung menggunakan formula AOAC (AOAC, 1990).

\subsection{Persiapan Analisis Komposisi Asam Lemak}

Analisis komposisi asam lemak dapat ditentukan berdasarkan AOCS Ce 1f-96 (AOCS, 1998). Sebanyak 0,05 g minyak dilarutkan dalam $1,5 \mathrm{ml} \mathrm{NaOH}-$ Metanolik $0,5 \mathrm{~N}$ yang kemudian divorteks dan dipanaskan di dalam penangas air pada suhu $100^{\circ} \mathrm{C}$ selama 5 menit. Campuran larutan tersebut ditambahkan BF3 sebanyak 2 ml dan kemudian dipanaskan pada suhu $100^{\circ} \mathrm{C}$ selama 30 menit. Setelah didinginkan pada suhu kamar, campuran tersebut ditambahkan iso-oktana sebanyak $2 \mathrm{ml}$ dan larutan $\mathrm{NaCl}$ sebanyak $5 \mathrm{ml}$. Larutan tersebut dikocok dan lapisan isooktana yang terbentuk diinjeksikan ke dalam kromatografi gas.

\subsection{Analisis Kromatografi Gas}

Analisis komposisi asam lemak dilakukan pada alat kromatografi gas menggunakan detektor FID dengan kolom DB-23 (30 m x 0,250 mm). Kolom diatur pada suhu $90^{\circ} \mathrm{C}$ selama 5 menit setelah injeksi dimana suhu program diatur pada kecepatan $7^{\circ} \mathrm{C}$ per menit hingga mencapai $208^{\circ} \mathrm{C}$ selama enam menit dengan total waktu kerja selama 27,86 menit. Gas helium digunakan sebagai gas pembawa dengan kecepatan 1,04 ml/menit dan total kecepatan mencapai $54,1 \mathrm{ml} / \mathrm{menit}$. Suhu detektor diatur pada suhu $260^{\circ} \mathrm{C}$.

\section{Hasil dan Pembahasan}

Sebanyak 56 sampel makanan dari 7 jenis makanan yang berbeda dianalisis dengan parameter pengujian yaitu total asam lemak jenuh, total asam lemak tidak jenuh tunggal dan total asam lemak tidak jenuh majemuk dalam satuan g per takaran saji sampel makanan.

\subsection{Produk Biskuit}

Komposisi total asam lemak dalam berbagai jenis biskuit dapat dilihat pada Tabel 1. Secara umum biskuit yang telah dianalisis mengandung kandungan asam lemak jenuh yang tinggi.

Tabel 1 : Komposisi asam lemak berbagai jenis biscuit per takaran saji.

\begin{tabular}{|c|c|c|c|c|c|}
\hline \multirow{2}{*}{ Biskuit } & \multicolumn{4}{|c|}{ Total Lemak (g) } & \multirow{2}{*}{ Minyak (g) } \\
\hline & ALJ & ALTT & ALTJM & ALT & \\
\hline Bi 1 & 1,721 & 0,452 & 0,153 & td & 2,326 \\
\hline Bi 2 & 0,729 & 0,678 & 0,206 & $\mathrm{td}$ & 1,614 \\
\hline Bi 3 & 1,259 & 1,210 & 0,496 & $\mathrm{td}$ & 2,965 \\
\hline $\mathrm{Bi} 4$ & 0,498 & 0,384 & 0,114 & $\mathrm{td}$ & 0,996 \\
\hline Bi 5 & 1,331 & 1,197 & 0,327 & $\mathrm{td}$ & 2,856 \\
\hline Bi 6 & 1,512 & 0,920 & 0,236 & $\mathrm{td}$ & 2,667 \\
\hline Bi 7 & 1,303 & 1,115 & 0,318 & $\mathrm{td}$ & 2,736 \\
\hline Bi 8 & 1,637 & 1,051 & 0,278 & 0,007 & 2,972 \\
\hline Bi 9 & 0,851 & 0,355 & 0,104 & 0,001 & 1,311 \\
\hline Bi 10 & 0,729 & 0,457 & 0,004 & 0,003 & 1,365 \\
\hline Bi 11 & 0,468 & 0,418 & 0,126 & $\operatorname{td}$ & 0,951 \\
\hline
\end{tabular}


Bi 12

0,558

0,203

0,060

td

0,829

Ket: ALJ = asam lemak jenuh; ALTJT = asam lemak tidak jenuh tunggal;

ALTJM = asam lemak tidak jenuh majemuk; ALT = asam lemak trans; $t d=$ tidak terdeteksi

Pada Tabel 1 dapat dilihat bahwa kandungan asam lemak jenuh dari seluruh sampel biskuit lebih tinggi sekitar dibandingkan dengan asam lemak tidak jenuh. Norhayati et al, (2011) menyatakan bahwa jumlah asam lemak jenuh yang tinggi dapat dikarenakan penggunaan minyak inti sawit atau hidrogenasi minyak inti sawit. Seluruh produk masih mengandung asam lemak jenuh kurang dari $20 \mathrm{~g}$ per takaran saji.

\subsection{Produk Mie}

Penggorengan mie dibutuhkan pada proses pembuatan mie, diduga beberapa produk mie menggunakan minyak goreng sawit (Berger, 2005). Hasil analisis komposisi asam lemak dari produk mie dapat dilihat pada Tabel 2.

Tabel 2.Komposisi asam lemak berbagai jenis mie per takaran saji.

\begin{tabular}{|c|c|c|c|c|c|}
\hline \multirow{2}{*}{ Mie } & \multicolumn{4}{|c|}{ Total Lemak (g) } & \multirow{2}{*}{ Minyak } \\
\hline & ALJ & ALTJT & ALTJM & ALT & \\
\hline $\mathrm{Nd} 1$ & 5,612 & 4,377 & 1,131 & 0,005 & 11,124 \\
\hline $\mathrm{Nd} 2$ & 8,907 & 6,787 & 1,731 & $\mathrm{td}$ & 17,424 \\
\hline $\mathrm{Nd} 3$ & 8,881 & 6,745 & 1,708 & $\mathrm{td}$ & 17,334 \\
\hline $\mathrm{Nd} 4$ & 5,716 & 4,512 & 1,177 & $\mathrm{td}$ & 11,405 \\
\hline $\mathrm{Nd} 5$ & 9,715 & 6,326 & 1,598 & 0,013 & 17,494 \\
\hline Nd 6 & 6,913 & 5,541 & 1,429 & $\mathrm{td}$ & 13,883 \\
\hline $\mathrm{Nd} 7$ & 6,022 & 4,563 & 1,092 & 0,005 & 11,682 \\
\hline $\mathrm{Nd} 8$ & 6,862 & 5,373 & 1,351 & 0,005 & 13,589 \\
\hline
\end{tabular}

Ket: ALJ = asam lemak jenuh; ALTJT = asam lemak tidak jenuh tunggal; ALTJM = asam lemak tidak jenuh majemuk; ALT = asam lemak trans; $t d=$ tidak terdeteksi

Pada Tabel 2 dapat dilihat bahwa kandungan yang seimbang antara asam lemak jenuh dan asam lemak tidak jenuh, diduga bahwa ketika proses penggorengan mie minyak yang digunakan adalah minyak goreng sawit (Gunstone, 2002). Seluruh produk masih mengandung asam lemak jenuh kurang dari $20 \mathrm{~g}$ per takaran saji.

\subsection{Produk Cokelat}

Total komposisi asam lemak jenuh dari produk cokelat dapat dilihat pada Tabel 3. Seluruh produk cokelat yang telah dianalisis mengandung jumlah asam lemak jenuh yang sangat tinggi. Hal tersebut dapat dikarenakan adanya kombinasi campuran dari lemak cokelat dan minyak inti sawit terhidrogenasi pada proses pembuatan produk cokelat (Aftab et al., 2013; Hasibuan et al., 2014). Seluruh produk masih mengandung asam lemak jenuh kurang dari $20 \mathrm{~g}$ per takaran saji.

Tabel 3. Komposisi asam lemak berbagai jenis cokelat per takaran saji.

\begin{tabular}{|c|c|c|c|c|c|}
\hline \multirow{2}{*}{ Cokelat } & \multicolumn{4}{|c|}{ Total Lemak (g) } & \multirow{2}{*}{ Minyak (g) } \\
\hline & $\overline{\text { ALJ }}$ & ALTJT & ALTJM & $\overline{\text { ALT }}$ & \\
\hline Cho 1 & 3,288 & 1,316 & 0,129 & td & 4,733 \\
\hline Cho 2 & 9,054 & 4,636 & 0,571 & $\mathrm{td}$ & 14,261 \\
\hline Cho 3 & 3,332 & 1,552 & 0,148 & $\mathrm{td}$ & 5,019 \\
\hline
\end{tabular}

Ket: ALJ = asam lemak jenuh; ALTJT = asam lemak tidak jenuh tunggal; ALTJM = asam lemak tidak jenuh majemuk; $\mathrm{ALT}=$ asam lemak trans; $\mathrm{td}=$ tidak terdeteksi 


\subsection{Produk Makanan Ringan}

Komposisi asam lemak total dari beberapa produk makanan ringan dapat dilihat pada Tabel 4.

Tabel 4. Komposisi asam lemak berbagai jenis makanan ringan per takaran saji

\begin{tabular}{llllll}
\hline \multirow{2}{*}{ Makanan Ringan } & \multicolumn{3}{c}{ Total Lemak } & \multirow{2}{*}{ Minyak (g) } \\
\cline { 2 - 5 } & ALJ & ALTJT & ALTJM & ALT & \\
\hline Sn 1 & 2,582 & 2,436 & 0,516 & td & 5,526 \\
Sn 2 & 1,830 & 1,763 & 0,448 & td & 4,042 \\
Sn 3 & 1,972 & 1,926 & 0,479 & td & 4,377 \\
Sn 4 & 2,007 & 1,925 & 0,477 & td & 4,409 \\
Sn 5 & 2,902 & 2,761 & 0,656 & 0,004 & 5,994 \\
Sn 6 & 2,355 & 2,208 & 0,611 & td & 5,174 \\
Sn 7 & 3,340 & 3,313 & 0,832 & 0,003 & 7,491 \\
Sn 8 & 4,078 & 3,859 & 0,906 & td & 8,843 \\
Sn 9 & 2,251 & 2,071 & 0,269 & 0,004 & 4,598 \\
Sn 10 & 1,806 & 1,633 & 0,435 & 0,002 & 3,877 \\
\hline
\end{tabular}

Ket: ALJ = asam lemak jenuh; ALTJT = asam lemak tidak jenuh tunggal; ALTJM = asam lemak tidak jenuh majemuk; ALT = asam lemak trans; td = tidak terdetek

Data menunjukkan bahwa kandungan asam lemak jenuh dan asam lemak tidak jenuh memiliki perbandingan yang seimbang. Hal tersebut dapat dikarenakan seluruh produk makanan ringan mengalami proses penggorengan dengan menggunakan minyak kelapa sawit (Gunstone, 2002). Penggunaan minyak goreng sawit pada makanan ringan ternyata tidak mempengaruhi jumlah asupan total asam lemak sehingga asam lemak jenuh masih dalam batas aman.

\subsection{Produk Margarin}

Margarin merupakan salah satu produk turunan minyak kelapa sawit yang mengandung lebih dari $80 \%$ lemak baik hewan maupun nabati. Komposisi asam lemak produk margarin dapat dilihat pada Tabel 5.

Tabel 5. Komposisi asam lemak berbagai jenis margarin per takaran saji.

\begin{tabular}{|c|c|c|c|c|c|}
\hline \multirow{2}{*}{ Margarin } & \multicolumn{4}{|c|}{ Total Lemak (g) } & \multirow{2}{*}{ Minyak (g) } \\
\hline & $\overline{\text { ALJ }}$ & ALTJT & ALTJM & ALT & \\
\hline Ma 1 & 11,791 & 8,056 & 1,988 & 0,025 & 21,860 \\
\hline Ma 2 & 5,763 & 4,593 & 1,184 & $\mathrm{td}$ & 11,540 \\
\hline Ma 3 & 12,642 & 7,908 & 1,847 & 0,114 & 22,511 \\
\hline Ma 4 & 6,122 & 3,183 & 0,881 & $\mathrm{td}$ & 10,186 \\
\hline Ma 5 & 13,255 & 6,902 & 1,752 & $\mathrm{td}$ & 21,909 \\
\hline Ma 6 & 17,166 & 6,077 & 1,061 & $\mathrm{td}$ & 24,304 \\
\hline Ma 7 & 13,932 & 7,234 & 1,578 & $\mathrm{td}$ & 22,755 \\
\hline Ma 8 & 11,219 & 7,877 & 1,849 & $\mathrm{td}$ & 20,944 \\
\hline
\end{tabular}

Ket: ALJ = asam lemak jenuh; ALTJT = asam lemak tidak jenuh tunggal; ALTJM = asam lemak tidak jenuh majemuk; ALT = asam lemak trans; td $=$ tidak terdeteksi

Margarin mengandung asam lemak jenuh yang tinggi sekitar 50-70\% dari total lemak. Sekitar 2 dari 8 margarin mengandung asam lemak jenuh yang rendah kurang dari $10 \mathrm{~g}$ per takaran saji. Namun bila dilihat dari komposisi 
lemak yang diperoleh, seluruh margarin diproduksi dari campuran partially hydrogenated vegetable dan minyak kelapa sawit serta adanya tambahan lemak susu (Anwar et al, 2006).

\subsection{Produk Minyak Goreng}

Total komposisi asam lemak dari beberapa produk minyak goreng dapat dilihat pada Tabel 6. Proporsi yang seimbang antara asam lemak jenuh dan asam lemak tidak jenuh diindikasikan penggunaan minyak kelapa sawit menjadi bahan baku utama pada pembuatan produk minyak goreng atau kombinasi dengan minyak nabati lainnya (Dauqan et al., 2011).

Tabel 6. Komposisi asam lemak berbagai jenis minyak goreng per takaran saji

\begin{tabular}{|c|c|c|c|c|c|}
\hline \multirow{2}{*}{ Minyak Goreng } & \multicolumn{4}{|c|}{ Total Lemak (g) } & \multirow{2}{*}{ Minyak (g) } \\
\hline & $\overline{\mathbf{A L J}}$ & ALTJT & ALTJM & ALT & \\
\hline Fo 1 & 4,681 & 4,969 & 1,346 & $\mathrm{td}$ & 11 \\
\hline Fo 2 & 2,137 & 2,236 & 0,627 & $\mathrm{td}$ & 5 \\
\hline Fo 3 & 4,671 & 4,978 & 1,351 & $\mathrm{td}$ & 11 \\
\hline Fo 4 & 4,262 & 4,485 & 1,244 & $\mathrm{td}$ & 10 \\
\hline Fo 5 & 6,488 & 5,834 & 1,678 & $\mathrm{td}$ & 14 \\
\hline Fo 6 & 6,035 & 6,272 & 1,693 & $\mathrm{td}$ & 14 \\
\hline Fo 7 & 6,119 & 6,206 & 0,851 & $\mathrm{td}$ & 14 \\
\hline Fo 8 & 5,999 & 6,276 & 1,650 & $\mathrm{td}$ & 14 \\
\hline Fo 9 & 6,085 & 6,183 & 1,732 & $\mathrm{td}$ & 14 \\
\hline Fo 10 & 5,867 & 7,132 & 1,998 & $\mathrm{td}$ & 15 \\
\hline Fo 11 & 6,423 & 6,841 & 1,730 & $\mathrm{td}$ & 15 \\
\hline Fo 12 & 5,802 & 6,292 & 1,769 & $\mathrm{td}$ & 14 \\
\hline
\end{tabular}

Ket: ALJ = asam lemak jenuh; ALTJT = asam lemak tidak jenuh tunggal;

ALTJM = asam lemak tidak jenuh majemuk; ALT = asam lemak trans;

$\mathrm{td}=$ tidak terdeteksi

\subsection{Produk Shortening}

Komposisi asam lemak dari berbagai jenis shortening dapat dilihat pada Tabel 7. Seluruh produk shortening mengandung asam lemak jenuh yang tinggi tetapi tidak mengandung asam lemak trans. Hal tersebut dapat terjadi karena penggunaan bahan baku pembuatan shortening berasal dari campuran fraksi minyak kelapa sawit seperti RBD palm oil, RBD palm olein, dan RBD palm stearin. Fraksi-fraksi turunan minyak kelapa sawit tersebut tidak melalui proses hidrogenasi sehingga tidak terjadi oksidasi untuk membentuk asam lemak trans (Hunter, 2006).

Tabel 7. Komposisi asam lemak berbagai jenis shortening per takaran saji

\begin{tabular}{cccccc}
\hline \multirow{2}{*}{ Shortening } & \multicolumn{4}{c}{ Total Lemak (g) } & \multirow{2}{*}{ Minyak (g) } \\
\cline { 2 - 5 } & ALJ & ALTJT & ALTJM & ALT & td \\
Sh 1 & 14,826 & 8,277 & 1,897 & 25 \\
Sh 2 & 14,963 & 8,059 & 1,977 & td & 25 \\
Sh 3 & 13,651 & 10,851 & 0,498 & td & 25 \\
\hline
\end{tabular}

Ket: ALJ = asam lemak jenuh; ALTJT = asam lemak tidak jenuh tunggal;

ALTJM = asam lemak tidak jenuh majemuk; ALT = asam lemak trans;

$\mathrm{td}=$ tidak terdeteksi 


\section{Kesimpulan}

Seluruh produk yang dilakukan pengujian mengandung turunan minyak kelapa sawit sebagai sumber lemak dengan komposisi yang dapat dilihat pada kemasan. Seluruh produk biskuit, mie, cokelat, dan makanan ringan mengandung asam lemak jenuh yang relatif lebih rendah dibandingkan dengan produk margarin dan shortening. Berbeda dengan minyak goreng yang memiliki kandungan asam lemak jenuh dan asam lemak tidak jenuh seimbang karena menggunakan minyak kelapa sawit sebagai bahan baku utama dan minyak nabati lainnya sebagai bahan tambahan. Meskipun demikian, seluruh produk makanan di Indonesia masih mengandung asam lemak jenuh dengan kategori rendah karena berada pada angka kurang dari $20 \mathrm{~g}$ per takaran saji sesuai regulasi Nutrient Reference Values (NRVs).

\section{Daftar Pustaka}

[1] Aftab, A.K.,. Sherazi,S.T.H., Rubiza,S., Razia,S., Ambrat and Arfa,Y. (2013). Consequence of Fatty Acid Profile Including Trans Fat in Chocolate and Pastry Samples. International Food Research Journal. 20(2): 601-605

[2] Anwar, F., Bhanger,M.I., Iqbal,S., and Sultana,B.(2006). Fatty Acid Composition of Different Margarines and Butter From Pakistan with Special Emphasis on Trans Unsaturated Contents. Journal of Food Quality. 29(1): 87-96

[3] American Oil Chemist"s Society. (1998). Official Methods and Recommended Practices of the American Oil Chemistes. 4th ed. American Oil Chemist's Society. Champaighn. IL

[4] Association of Analytical Communities. (1990). AOAC Methods of Analysis. 15th Edition. Washington DC: Association of Official Agriculture.

[5] Berger, K.G. (2005). The Use of Palm Oil in Frying. Malaysian Palm Oil Promotion Council. Page 33.Cameron-Smith, D., and A. Sinclair. 2006. Trans Fats in Australian Fast Foods. Letters: The Medical Journal of Australia. 185(6): 293

[6] Dauqan, M.A.E., Sani, H.A., Aminah., Abdullah., and. Kasim, Z.M. (2011). Fatty Acid Composition of Four Different Vegetable Oils (Red Palm Olein, Palm Olein, Corn Oil and Coconut) by Gas Chromatography. 2nd International Conference on Chemistry and Chemical Engineering. 14: 31-34

[7] EFSA Panel on Dietetic Products, Nutrition, and Allergies (NDA). (2010). Scientific Opinion on DietaryReference Values for fats, including saturated fatty acids, polyunsaturated fatty acids, monounsaturated fatty acids, trans fattyacids, and cholesterol. EFSA Journal; 8(3):1461. [107 pp.].

[8] Gunstone, F. (2002). Vegetable Oils in Food Technology: Composition, Properties and Uses. Blackwell Publishing : CRC Press USA. Page 59

[9] Hasibuan, H.A., Sundari, Y., and Silalahi, J. 2014. Kadar Asam Lemak Trans Pada Cocoa Butter Substitute Indonesia Dan Produk Coklatnya. Warta PPKS. 19(1): 39-48

[10] Hunter, J.E. 2006. Dietary trans fatty acids: Review of recent human studies and food industry responses. J. Lipid. 41(11): 967-992

[11] Lichtenstein, A.H., Appel, L.J., Brands, M., Carnethon, M., Daniels, S., Franch, H.A., Franklin, B., Kris-Etherton, P., Harris, W.S., Howard, B., Karanja, N., Lefevre, M., Rudel, L., Sacks, F., Horn, L.V., Winston, M., dan Wylie-Rosett, J.(2006). Diet and Lifestyle Recommendations Revision 2006: A scientificstatement from the American Heart Association Nutrition Committee.Circulation. 114: 82-96

[12] Mayes, P.A. (2003). Biosintesis asam lemak. In: Murrat, R.K., Granner, D.K., Mayes, P.A., dan Rodwell, V.W. 2003. Biokimia. Jakarta

[13] Norhayati, M., A. Azrina., M.E. Norhaizam and R.R. Muhammad. (2011). Trans Fatty Acids Content of Biscuits Commercially Available in Malaysia Market and Comparison with Other Countries. International Food Reseaarch Journal. 18(3): 1097-1103

[14] Nusantoro, B.P. (2009). Physicochemical Properties of Palm Stearin and Palm Mid FractionObtained by Dry Fractionation. Agritech, Vol. 29, No. 3

[15] Sartika, R.A.D. (2008). Pengaruh Asam Lemak Jenuh, Tidak Jenuhdan Asam Lemak Trans terhadap Kesehatan. Jurnal Kesehatan Masyarakat Nasional Vol. 2, No. 4 